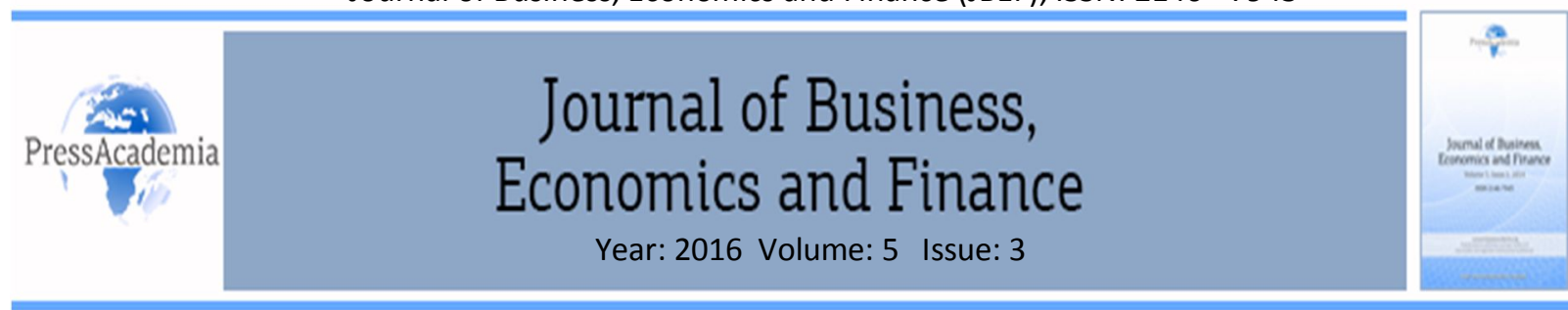

\title{
MODELING DAILY AMMAN STOCK EXCHANGE VOLATILITY FOR SERVICES SECTOR
}

\section{DOI: 10.17261/Pressacademia.2016321976}

\author{
Salih Turan Katircioglu ${ }^{1}$, Mansour Mohammad Al-khaza'leh ${ }^{2}$ \\ ${ }^{1}$ Eastern Mediterranean University, salihk@emu.edu.tr \\ ${ }^{2}$ Eastern Mediterranean University, mansour454423@yahoo.com
}

\begin{abstract}
There are many forecasting techniques that can be used to help the investment community in building their policies in the future, which lead to an appropriate choices of the assets involved in the portfolios, managing it, and pricing these assets accurately. In this paper we are trying to afford one of these methods recognized as ARIMA model, which is used in analyzing financial time series data. The target of this paper is forecasting services sector volatility in Amman Stock Exchange. As a result investment community can rely on this type of analysis to make the future prospects of selling and buying financial securities. Using historical indices data accumulated daily from the web site of Amman Stock Exchange for period 3/1/2010-10/5/2015. Stationarity achieved at level for services sector , and then use a minimum mean square error, t-statistics value and $p$-statistics value to choose the best ARIMA models at $95 \%$ confidence interval. The resulted models for this study for services sector is $\operatorname{ARIMA}(0,0,1)$, lastly, the best ARIMA model was formed and tabulated in the entire paper.
\end{abstract}

Keywords: Volatility, ARIMA Model, Financial Time Series, Forecasting.

JEL Classification: G17, G19

\section{INTRODUCTION}

Forecasting volatility has a very important role in the investment community in recent days because the decision of portfolio management, risk management, and pricing of assets depend on this forecasting to achieve the goals of investors in order to make their investments, or to reduce losses that they may meet in the future, that is because any wrong decision investors take maybe cause a cost for all the members of investment community, which leads to a confused situation in the whole country economy, as a result of this, the confidence of improvements in the near future will be hard to get. Huge changes of securities prices put investors and decision makers in a confused situation when they plan to buy or sell a set of financial securities in ASE or in any other financial market whether in emerging or developed markets. The rest of this paper is organized as follows. Section 2 provides a review of literature on modeling volatility. Section 3 discusses the data used in this study and the methodology. Empirical findings are provided in section 4 . The final section concludes.

\section{LITERATURE REVIEW}

Al-Zeaud (2011) studied ARIMA model in modeling and forecasting the banks sector volatility for the Amman stock Exchange (ASE). The result proved that the tentative appropriate ARIMA models at 95\% confidence interval is ARIMA $(2,0,2)$ model. Ritab S., et al ,(2007) The main features of this study are the utilization of the ARIMA model and the employment of the co-integration and unit root tests to distinguish the stationary of the time series for the volatility ASE. Alshiab ,2006)studied Autocorrelation function and partial autocorrelation functions analysis tests employed to determine whether the data set stationary or not stationary. The resulted 
model was studied the predictability of Amman stock exchange (ASE) Performance, also he studied the expectedness of ASE Performance: then, he used a Univariate Autoregressive Integrated Moving Average (ARIMA) model; he examined the univariate ARIMA forecasting model, by means of the ASE general daily index

within the period $4 / 1 / 2004$ and 10/8/2008. Furthermore, he found the forecast was not consistent with actual performance during the same period of the prediction. Alfaki and Mustafa (2015) introduced a short review about Box-Jenkins models as acknowledged ARIMA models(Autoregressive Integrated Moving Average). It is a good technique to anticipate for stationary and non-stationary time series. According to the data which obtained from the monthly sales for Naphtha product in (Azzawiya Oil Refining Company - Libya), then they specify a tentative proper model for the monthly sales. The consequences of this study showed that the suitable and efficient model to correspond to the data of the time series according to AIC, SIC, and MSE criteria with the minimum values as well as the Box-ljung test is the $\operatorname{ARIMA}(1,1,1)$. A model that can be used in volatility must have the ability of forecasting it. In general a volatility model is engaged with predicting the magnitude of returns in absolute, Such forecasts work an essential mission in risk management,derivative pricing and hedging, market making, market timing, portfolio selection and many financial actions.Stephen.S and John.K.(2007). Juncal C., et al (2006) studied the cause of change in volatility dynamic behavior of emerging market Volatility. They investigated whether the dynamic_behavior of stock market volatility in six emerging economies (Argentina, Brazil, Chile, Korea, Mexico, and Thailand) has changed over the period 1976:012004:12. This period corresponds to years of profound development of both financial and the productive sides in these emerging countries, but also to the years of the major financial crises. They suggested in their analysis that changes in volatility behavior, while indeed present, may have been overstated in the past: simple specifications account for most of the dynamics of stock market volatility and therefore become powerful tools for volatility analysis. Additionally, they showed that the financial liberalization of emerging markets has generally reduced the level of market volatility and its sensitivity to news. High frequency data that used in volatility forecasting can mainly be separated into two major approaches; the first one is the reduced-form approach which has included the cases where the realized measures are patterned with a time series model (e.g. ARIMA) and the estimated model is used to generate volatility forecasts. Andersen et al. (2003) built and investigated long-memory Gaussian vector (VAR) models for a vector of realized variances. A consistent kind of reduced-form volatility predictions are the regression that depends on forecasts; while the second approach is the model-based approach for volatility forecasting which is constructed from a model for returns, such as a GARCH type model that identifies the whole

\section{DATA AND METHODOLOGY}

The value of financial properties relies on the expected volatility of returns. Volatility can be defined as:

$$
r_{t}=\left|\log \left(x_{t}\right)-\log \left(x_{t-1}\right)\right|
$$

where: $r_{t}$ is the returns, $x_{t}$ is the observation at time $t, x_{t-1}$ is the observation time $t-1, \log$ is the logarithm and |. $\mid$ is the absolute value.

In the case of low-volatility state, the square root of variance of returns is diminutive and determining whether the economy has interchanged to the high-volatility or not. It is very difficult to achieve a huge amounts of gains in this case, so their incidence rapidly shows to investors that the economy is in the high-volatility situation. In the large-volatility situation, petite returns do not immediately show that the economy has interchanged situations since a reasonable possibility of getting a small return exists even though the standard deviation of returns is high. A financial time series declares two important features; nonstationary and time varying volatility. There is no doubt that fluctuations of the stocks in the financial markets have a huge effects on the economic policymakers decisions particularly when it differs from what they expected. The improbability of future cash flows resulted comparatively from a privileged ranks of volatility, as a result it will be reflected on the economic conditions which cause and form a signs of large amount of volatility, that is called a high volatility channel (pending crisis also). on the other hand the other type is known as a low volatility channel which may also cause a crisis. Danielsson et al. (2012) suggest a theoretical settings, low risk level persuades economic decision managers to raise levels of uncertainty, which then endogenously affects the probability of future surprises. These arguments suggest that the high volatility channel is most important closer to a crisis, while the low channel is most important further than from a crisis. Low volatility encourage risk-taking, only appears at some stage in a crisis, while high volatility is an indicator of a pending crisis. 
Many predicting methods are employed in statistics (Random Walk Model, Moving Average Model, Weighted Moving Average Model, Regression Model, Autoregressive Conditional Heteroskedastic model, Exponential Generalized Autoregressive conditional heteroskedasticity model, Autoregressive Integrated Moving Average model).In this paper, Box-Jenkins method introduced. The Univariate Box -Jenkins models resulted from employing conventional probability theory and mathematics and statistics. Secondly, ARIMA models are a family unit of models, not just a single model. Box and Jenkins have developed an approach that guides the analyst in choosing one or more appropriate models out of this larger family of models. Thirdly, it can be shown that a tentative ARIMA model creates a best possible univariate forecasts. In other words, there is no standard single-series model be able to provide prediction with a minimum mean-squared forecast error (i.e., forecast error variance) (Pankratz, 1983).. The steps of Box and Jenkins for getting a superior model are as the following: Identification: through employing graphics of both autocorrelation and partial autocorrelation functions which will lead us to pick a category of simple ARIMA models in order to determine the values of $p$,q, and d. Estimation: The phis and thetas of the picked model are estimated according to maximum likelihood practice as determined in BOX-Jenkins 1976. Diagnostic checking The fitted model is tested for inadequacies by regarding the autocorrelations of the residual or error or values.

The most common ARIMA model included three parameters: $p, d$, and $q$ where $p$ is the number of autoregressive parameters, $d$ is the number of differencing parameters and $q$ is the number of moving average parameters. A general ARIMA model is in the form (Bruce et al, 2005; and John and David, 2003):

$$
z_{t}=C+\varphi_{1} z_{t-1}+\varphi_{2} z_{t-2}+\ldots+\varphi_{p} z_{t-p}+a_{t}-\theta_{1} a_{t-1}-\theta_{2} a_{t-2}-\ldots-\theta_{p} a_{t-q}
$$

Where; $t$ : is the periodic time, $z_{t}$ : is the numerical value of an observation, $\varphi_{i}:$ for $i=1,2, \ldots, p$ are the autoregressive parameters, $\theta_{j}$ :for $j=1,2, \ldots, q$ are the moving average parameters, $a_{t}$ :is the shock element at time $t$. The linear multiple regression performed to estimate the parameters $\varphi_{i}$ and $\theta_{j}$ for a fixed $p$ and $q$, as follows

$$
\hat{z}_{t}=\mu+\varphi_{1} z_{t-1}+\varphi_{2} z_{t-2}+\ldots+\varphi_{p} z_{t-p t}-\theta_{1} a_{t-1}-\theta_{2} a_{t-2}-\ldots-\theta_{p} a_{t-q}
$$

There are two phases to the identification of an appropriate Box - Jenkins model: changing the data if necessary into a stationary time series and determining the tentative model by observing the behavior of the autocorrelation and partial autocorrelation function. Box and Jenkins suggested the number of Lag to be no more than $n / 4$ autocorrelations; the autocorrelation coefficient measures the correlation between a set of observations and a lagged set of observation in a time series. The autocorrelation measures the correlation between a set of observations and a lagged set of observations in a time series The sample autocorrelation coefficients $r_{k}$ is an estimate of $\rho_{k}$ where

$$
r_{k}=\frac{\sum\left(z_{t}-\bar{z}\right)\left(z_{t+k}-\bar{z}\right)}{\sum\left(z_{t}-\bar{z}\right)^{2}}
$$

Where $z_{t}$ represent the data from the stationary time series. $z_{t+k}$ : The data from $\mathrm{k}$ time period ahead of $t$. $\bar{z}$ :The mean of the stationary time series. The ideas of partial autocorrelation analysis are used to measure the relationship between two variables when the effect of other variables has been uninvolved or seized fixed. The equation that gives a good estimate of the partial autocorrelation is

$$
\hat{\varphi}_{k k}=\frac{r_{k}-\sum_{j=1}^{k-1} \hat{\varphi}_{k-1, j} r_{k-j}}{1-\sum_{j=1}^{k-1} \hat{\varphi}_{k-1, j} r_{j}} \quad k=2,3, \ldots
$$


Where: $\quad \hat{\varphi}_{k j}=\hat{\varphi}_{k-1, j}-\hat{\varphi}_{k k} \hat{\varphi}_{k-1, k-j}$ and $k=3,4, \ldots ; j=1,2, \ldots, k-1$.

If a time series is stationary then the mean of any major subset of the series does not differ significantly from the mean of any other major subset of the series. Also if a data series is stationary then the variance of any major subset of the series will differ from the variance of any other major subset only by chance. However, most nonstationary series that arise in practice can be transformed into stationary series through relatively simple operations.Pankratz (1983)

\section{FINDINGS AND DISCUSSION}

There are many tests used to prepare the services sector for ASE using Univariate Box-Jenkins model. Firstly, the volatilities for services sector were computed according to Equation (1). Then, unit root test is used to check whether stationarity for this sector achieved or not. Lastly, the autocorrelation(ACF) and partial autocorrelation(PACF) were tested for services sector by testing the correlation between the index lags, they used to pick the appropriate tentative models.

\subsection{Descriptive Statistics of the Services Sector}

The first step of analyzing is built on the description statistics of the services sector. Table 1 showed the descriptive statistics for services sector. The original values of the services sector showed in Figure 1, and Figure 2 showed the plot of the volatilities for the services sector. Correspondingly, the minimum value is 1031.6 which is the least value regarding to the whole sectors in ASE, and the maximum value is 1835 which is also the least one. We noticed that the range of this sector is small. Similarly, the median is less than the mean that means the data is skewed to the right side. Also, the SE means which is equal to 4.78 . There is a positive kurtosis in this sector which means that the distribution has an approximately normality feature since it is closed to three.

Figure 1: Original Time Series Plot of the Services Sector

$S$

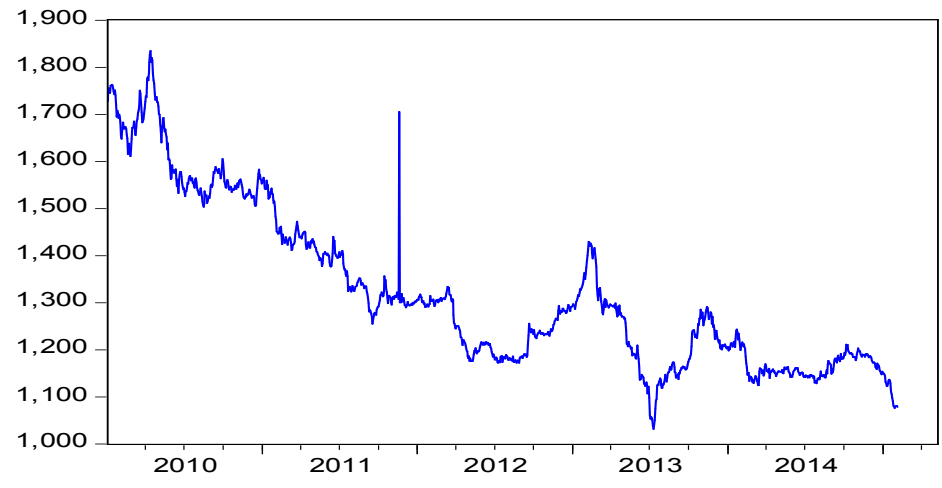

Table 1: Summary Descriptive Statistics for Services Sector of ASE 


\begin{tabular}{|c|r|r|}
\hline \multicolumn{2}{|c|}{ Descriptive Statistics for the banks sector } \\
\hline Estimators & Raw banks & $\begin{array}{c}\text { Banks } \\
\text { Volatility }\end{array}$ \\
\hline Mean & 1321.873 & 0.002317 \\
\hline Median & 1282.200 & 0.001633 \\
\hline Maximum & 1835 & 0.117854 \\
\hline Minimum & 1031.600 & 0.000000 \\
\hline Std. Dev. & 174.24 & 0.004866 \\
\hline Skewness & 0.884 & 19.70459 \\
\hline Kurtosis & 2.82 & 461.1355 \\
\hline Variance & 30359.58 & 0.0000237 \\
\hline SE mean & 4.78 & 0.002317 \\
\hline Total count & 1328 & 1327 \\
\hline
\end{tabular}

\subsection{Unit Root Test}

A unit root test determine whether a time series variable is non-stationary using an autoregressive model. One of the most famous tests is the augmented Dickey- Fuller test. This test used the existence of a unit root as the null hypothesis. It appears to be necessary to check the stationary in levels or at differences. The more negative ADF is the stronger the rejection of the hypothesis that said there is a unit roots at some level of confidence. The non-stationary time series could produce a weak result. In order to avoid the spurious correlation problem that resulted from a non-stationary variable it is essential to test for unit root of the services sector for ASE. In this study, the Augmented Dicky-Fuller (ADF) test is proposed to examine the stationarity (unit root) of the stock market index for services Ender (2004). Tables 2 showed the ADF test for stock market indices for services sector at levels $1 \%, 5 \%$ and $10 \%$ respectively. The results of this work out, strongly confirm at the standard $5 \%$ significance level that the stock index series are stationary in levels for services sector, so that no need to use any transformation on it.

Figure 2: Plot of the Volatility for Services Sector

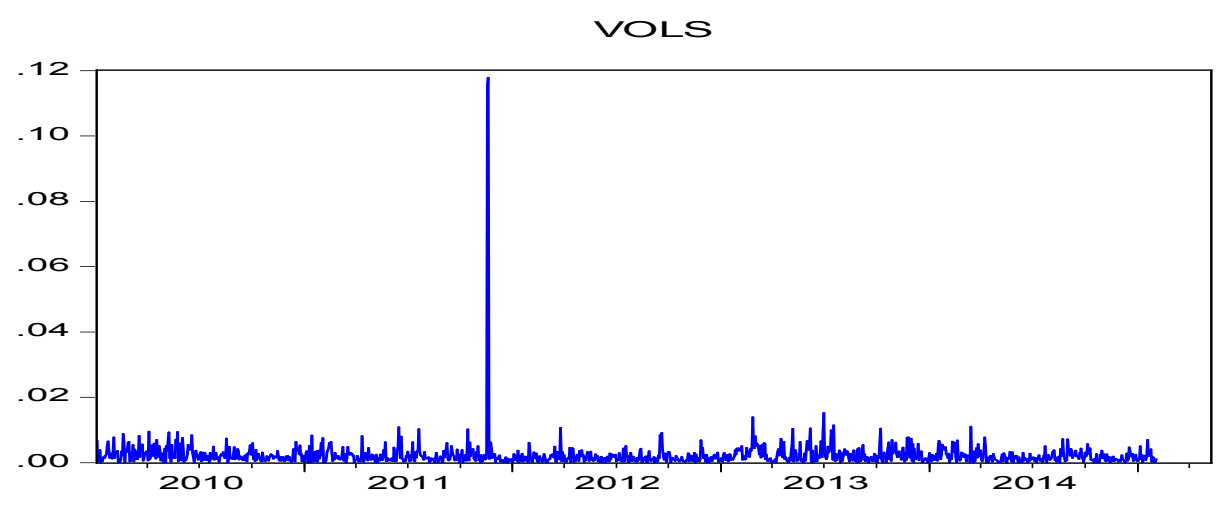

Table 2: Unit Root Test (stationary test) of Variable (services) at levels $1 \%, 5 \%$ and $10 \%$. 


\begin{tabular}{|c|c|c|c|c|}
\hline ADF Test Statistic & -16.51403 & \multicolumn{2}{|c|}{$1 \%$ Critical Value* } & -3.435082 \\
\hline level & & \multicolumn{2}{|c|}{ 5\% Critical Value } & -2.863517 \\
\hline services & & \multicolumn{2}{|c|}{$10 \%$ Critical Value } & -2.567872 \\
\hline \multicolumn{5}{|c|}{ *Mackinnon critical values for rejection of hypothesis of a unit root. } \\
\hline \multicolumn{5}{|l|}{ stationary } \\
\hline \multicolumn{5}{|c|}{ Augmented Dickey-Fuller Test Equation } \\
\hline \multicolumn{5}{|c|}{ Dependent Variable: D(SERVICES) } \\
\hline \multicolumn{5}{|l|}{ Method: Least Squares } \\
\hline Variable & Coefficient & Std. Error & t-Statistic & Prob. \\
\hline VOLS(-1) & -0.599176 & 0.036283 & -16.51403 & 0.0000 \\
\hline $\mathrm{D}(\mathrm{VOLS}(-1))$ & 0.219352 & 0.035085 & 6.252007 & 0.1972 \\
\hline $\mathrm{D}(\mathrm{VOLS}(-2))$ & -0.144960 & 0.029118 & -4.978380 & 0.3456 \\
\hline $\mathrm{D}(\mathrm{VOLS}(-3))$ & 0.077005 & 0.027439 & 2.806398 & 0.3334 \\
\hline C & 0.001389 & 0.000142 & 9.816849 & 0.0114 \\
\hline R-squared & 0.338884 & \multicolumn{2}{|c|}{ Mean dependent var } & 5.81E-07 \\
\hline Adjusted R-squared & 0.336877 & \multicolumn{2}{|c|}{ S.D. dependent var } & 0.005082 \\
\hline S.E. of regression & 0.004138 & \multicolumn{2}{|c|}{ Akaike info criterion } & -8.133213 \\
\hline Sum squared resid & 0.022573 & \multicolumn{2}{|c|}{ Schwarz criterion } & -8.113607 \\
\hline Log likelihood & 5385.120 & \multicolumn{2}{|c|}{ F-statistic } & 168.8993 \\
\hline Durbin-Watson stat & 1.991088 & \multicolumn{2}{|c|}{ Prob(F-statistic) } & 0.000000 \\
\hline
\end{tabular}

\subsection{Autocorrelation and Partial Autocorrelation}

The autocorrelation function (ACF) is the plot of autocorrelations and is very useful when checking also stationarity and when picking from among various nonstationary models. Autocorrelation is one of the vital instruments used in time series modeling. The partial autocorrelation function (PACF) is the plot of partial autocorrelations, and it is also one of the major tools in time series modeling, so the role of both ( ACF and PACF ) is to guide when choosing terms that should be included in an ARIMA model. Figure 3 showed the ACF for the indices of services volatility data in which it shows a large positive significant spike at lag 1 (this means that the autocorrelation of the successive pairs of observations within 1 time period is not within sampling error of zero). All of the other autocorrelations (for lags 2 to 15) are within the 95\% confidence limits. While, Figure 4 showed the PACF for the services volatility data which imply to a large positive significant spike at lag 1 (this means that the partial autocorrelation of the successive pairs of observations within 1 time period is not within sampling error of zero). All the other partial autocorrelations (for lags 2 to 15 ) are within the $95 \%$ confidence limits.

Figure 3: Autocorrelation Function for Services Volatility

SERVOL

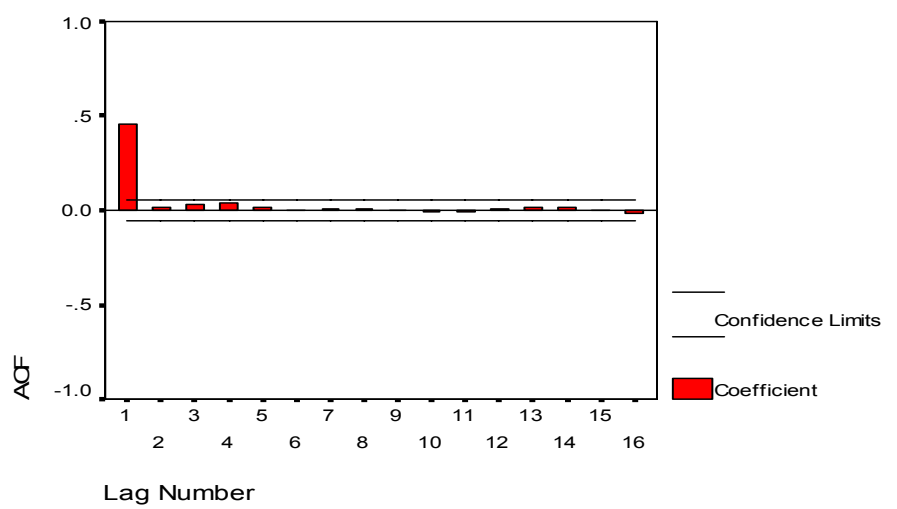

Figure 4: Partial Autocorrelation Function for Services Volatility 


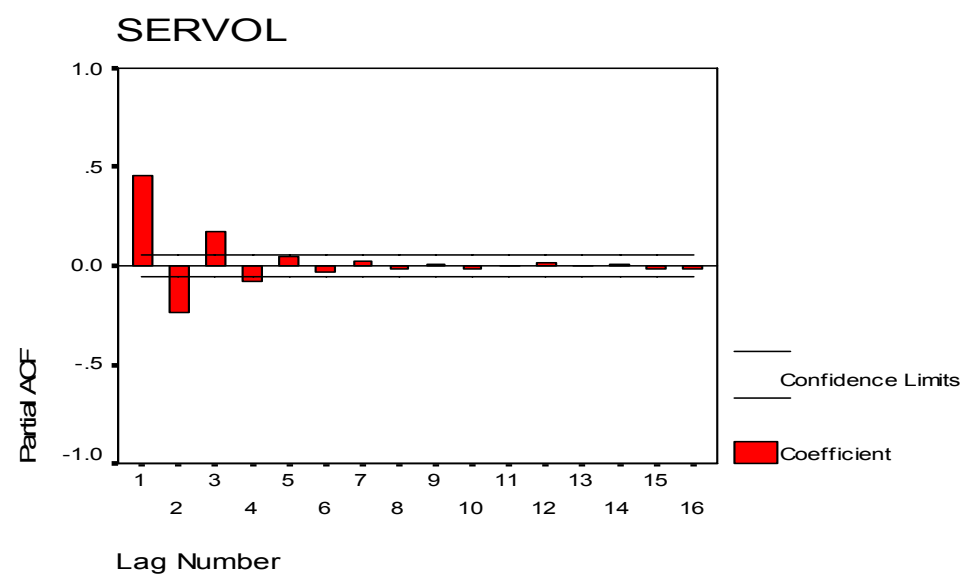

\subsection{ARIMA Model Analysis}

ARIMA models are one of the most general set of techniques used in a short time series predicting. We have used Equation 3.2. The most important general features of theoretical AR and MA depend on the behavior of autocorrelation and partial autocorrelation functions. Autoregressive as a part of ARIMA approaches to zero theoretically. But, after a small number of spikes cut off sharply to zero . the order of autoregressive function equals to the length of the last PACF spike. On the other hand Moving-average part of ARIMA model have an autocorrelation function that approaches to zero after a number of spikes. The lag length of the last ACF spike equals the MA order of the whole process. Mean square error can be computed as the average of the squared errors for all forecasts as an appraise of exactness of the appropriate model. Also it can be used to compare fits of different ARIMA models to pick the better one of them.

Suppose that $\theta$ denote any particular parameter in a Box-Jenkins model, let $\theta^{\prime}$ denote the point estimate of $\theta$, let $S_{\theta^{\prime}}$ denote the standard error of the point estimate $\theta^{\prime}$. Then the t-value associated with $\theta^{\prime}$ is the result of point estimate of $\theta$ divided by the standard error of the point estimate $\theta^{\prime}$. If we reject the null hypothesis that said the value of $\theta$ equal to zero in favor of the alternative hypothesis that said the value of $\theta$ does not equal to zero with a significance level $\alpha=0.05$, then we have fulfilled that $\theta$ is important in the model by using a test that allows only a 0.05 probability of concluding that $\theta$ is important when it is not. That is usually regarded as strong evidence that $\theta$ is important. A large absolute value of $\mathrm{t}$ implies a large $\theta^{\prime}$ which means that the value of $\theta$ is not zero, as a result we should reject the null hypothesis $\theta=0$, so, compulsory ARIMA model should contain $\theta$. Additionally, $\mathrm{p}$-value defined to be tested regarding to the level of significant $\alpha$.

Table 3 showed the all varieties of ARIMA models choices between the model $(0,0,0)$ to $(2,2,2)$ for the services volatility sector. The best model for services sector is ARIMA $(0,0,1)$, since this model gives the minimum mean square error which is $1 \times 10^{-4}$, then $\operatorname{ARIMA}(1,1,1)$. Despite some of these proposed models have a minimum MSE but their coefficients are not significant, as a result of this, the general formula for the $\operatorname{ARIMA}(0,0,1)$ is defined as follows:

$$
Z_{t}=\mu+a_{t}-\theta_{1} a_{t-1}
$$

Moreover, Table 4 showed the final estimate of the parameters for the services volatility sector data. 
Table 3: The Result of the Best ARIMA Model for Services Volatility

\begin{tabular}{|c|c|c|c|}
\hline Model (ARIMA) & MSE & Model (ARIMA) & MSE \\
\hline$(1,0,0)$ & 0.000018758 & $(2,0,2)$ with $\operatorname{ar}(1), \operatorname{ar}(2), \mathrm{ma}(1), \mathrm{ma}(2)$ & $\begin{array}{l}0.00001697 \\
1\end{array}$ \\
\hline$(1,0,1)$ & 0.000016971 & $(2,0,2)$ with $\operatorname{ar}(2), \mathrm{ma}(1), \mathrm{ma}(2)$ & $\begin{array}{l}0.00001697 \\
5\end{array}$ \\
\hline$(1,0,2)$ with $\operatorname{ar}(1), \mathrm{ma}(2)$ & 0.000016987 & $(2,0,2)$ with $\operatorname{ar}(1), \operatorname{ar}(2), \mathrm{ma}(2)$ & $\begin{array}{l}0.00001697 \\
1\end{array}$ \\
\hline$(1,0,2)$ with $\operatorname{ar}(1), \mathrm{ma}(1), \mathrm{ma}(2)$ & 0.000016949 & $(2,0,2)$ with $\operatorname{ar}(2), \mathrm{ma}(2)$ & $\begin{array}{l}0.00002364 \\
9\end{array}$ \\
\hline$(2,0,0)$ with $\operatorname{ar}(2)$ & 0.000023669 & $(2,0,1)$ with $\operatorname{ar}(2), \mathrm{ma}(1)$ & $\begin{array}{l}0.00001697 \\
5\end{array}$ \\
\hline$(2,0,0)$ with , $\operatorname{ar}(1), \operatorname{ar}(2)$ & 0.00001769 & $(2,0,1)$ with $\operatorname{ar}(1) \operatorname{ar}(2), \mathrm{ma}(1)$ & $\begin{array}{l}0.00001697 \\
5\end{array}$ \\
\hline$(0,0,1)$ with $\mathrm{ma}(1)$ & 0.0000169826 & $(0,0,2)$ with $\mathrm{ma}(2)$ & $\begin{array}{l}0.00002365 \\
1\end{array}$ \\
\hline
\end{tabular}

Table 4: Final Estimate of Parameters of the Services Volatility for ASE

\begin{tabular}{|l|l|l|l|l|}
\hline \multicolumn{5}{|l|}{ Final Estimates of Parameters } \\
\hline Type & Coef & SE Coef & T & P \\
\hline MA 1 & 0.622466 & 0.021443 & 29.02852 & 0.0000 \\
\hline Constant & 0.002317 & 0.000184 & 12.61553 & 0.0000 \\
\hline
\end{tabular}

Based on the Table 3 the ARIMA $(0,0,1)$ model can be derived. In order to check the adequacy of a Box-Jenkins model is to analyze the residuals $\left(Y_{t}-\hat{Y}_{t}\right)$. Figures 5 and 6 showed the residuals of ACF and PACF respectively for the volatility services sector. The residuals ACF and PACF for volatility services sector are indicated significant. Thus, the residuals are random and the model is a good fit to the data. More ever, the spikes lie inside the confidence limits.

\section{Figure 5: Autocorrelation of Residuals: Services Volatility Sector}

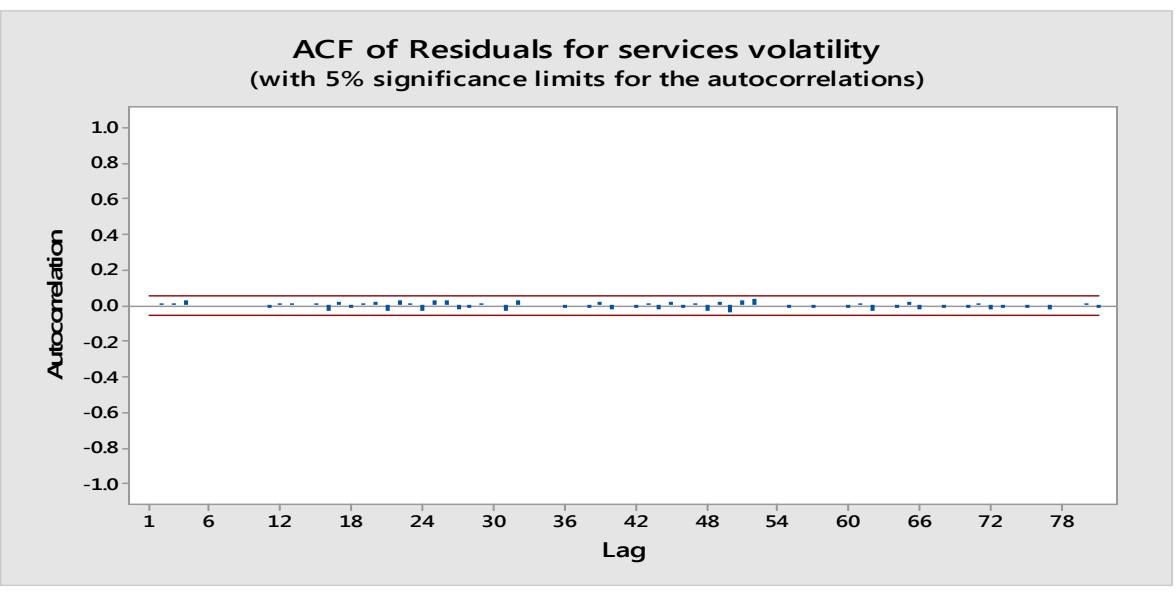




\section{Figure 6: Partial Autocorrelation of Residuals: Services Volatility}

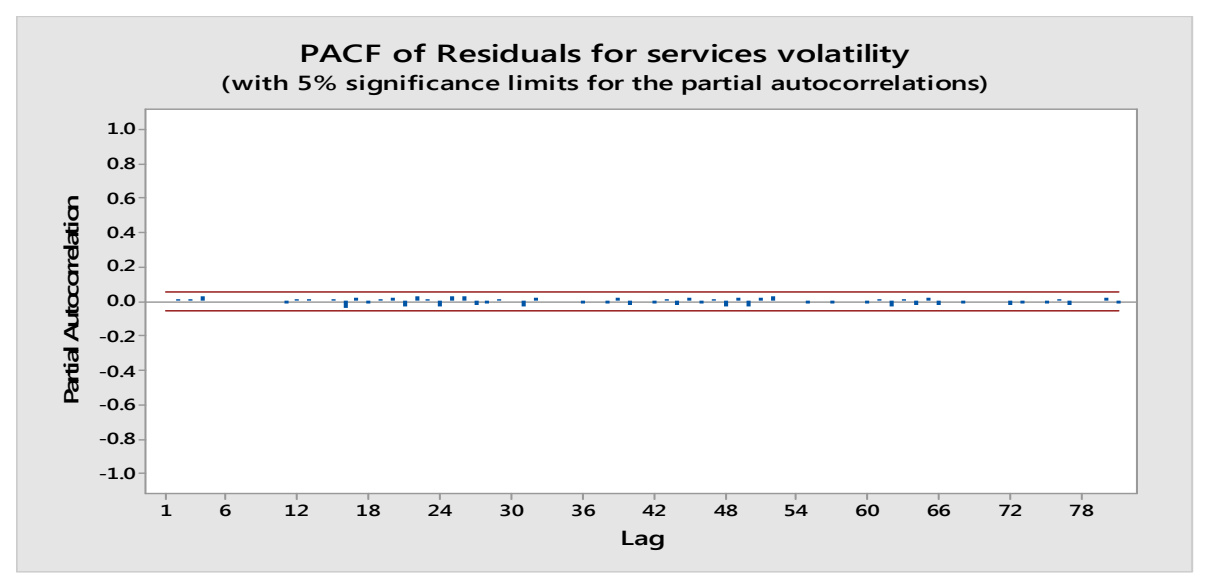

The four-in-one residual plot is showed in Figure 7. The normal probability plot indicated the residuals are normally distributed. Moreover, the fit regression line showed the residuals are closed to the straight line. The histogram indicated approximately the whole data centered on the mean of data. The residuals versus fitted values indicated the variance is approximately constant. The last graph showed the residuals versus order observations which are daily for services volatility sector, it is clear the whole residuals centered on and near to the $\mathrm{x}$ - axis.

At forecasting stage, the fitted model has been selected; it can be employed to construct forecasts for future time periods for the services volatility sector. The final model for the volatility services sector is demonstrated in equation 8 . Whereas, Figure 8 showed the plot of the actual and predicted values for the volatility services sector, the $95 \%$ percent prediction interval for the forecasts also are computed. Since, the values of the lower interval are negative sign, we can ignore these boundaries.

\section{Figure 7: Residuals Plots: Services Volatility}

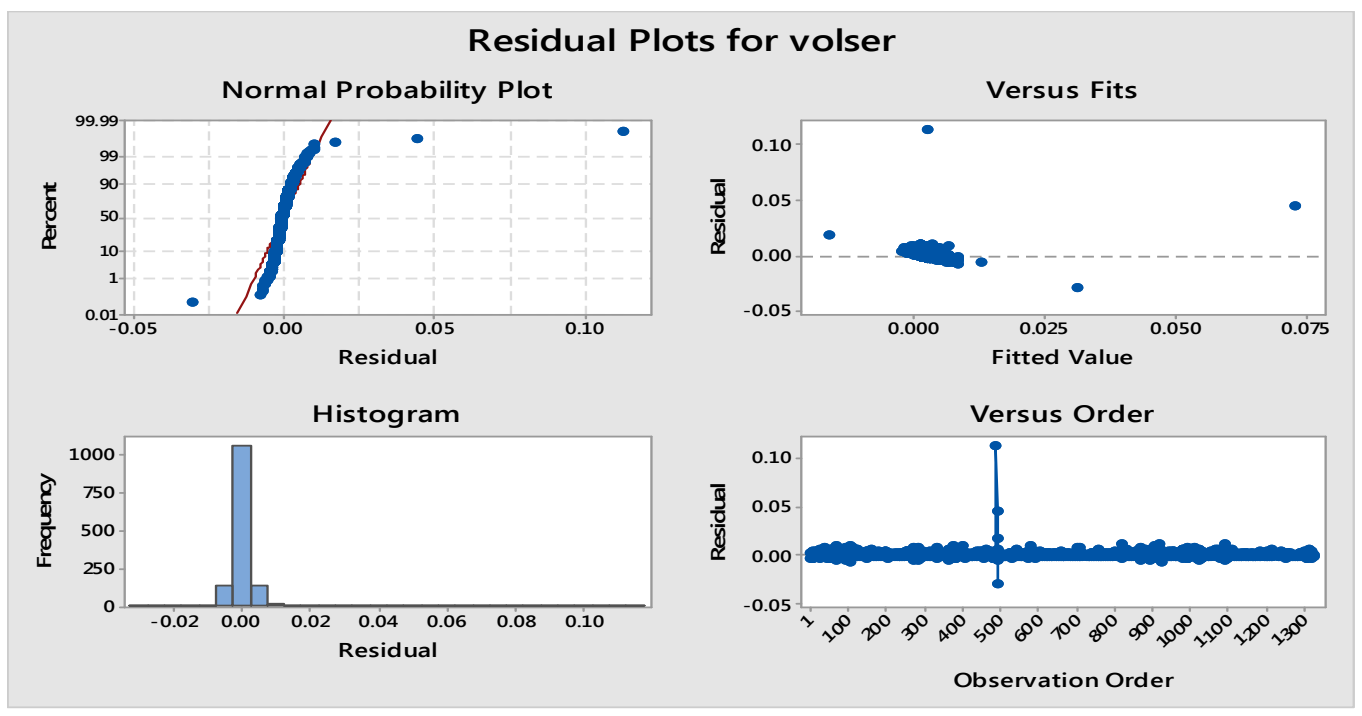


Figure 8: Actual and Forecasts Volatility Services for ASE

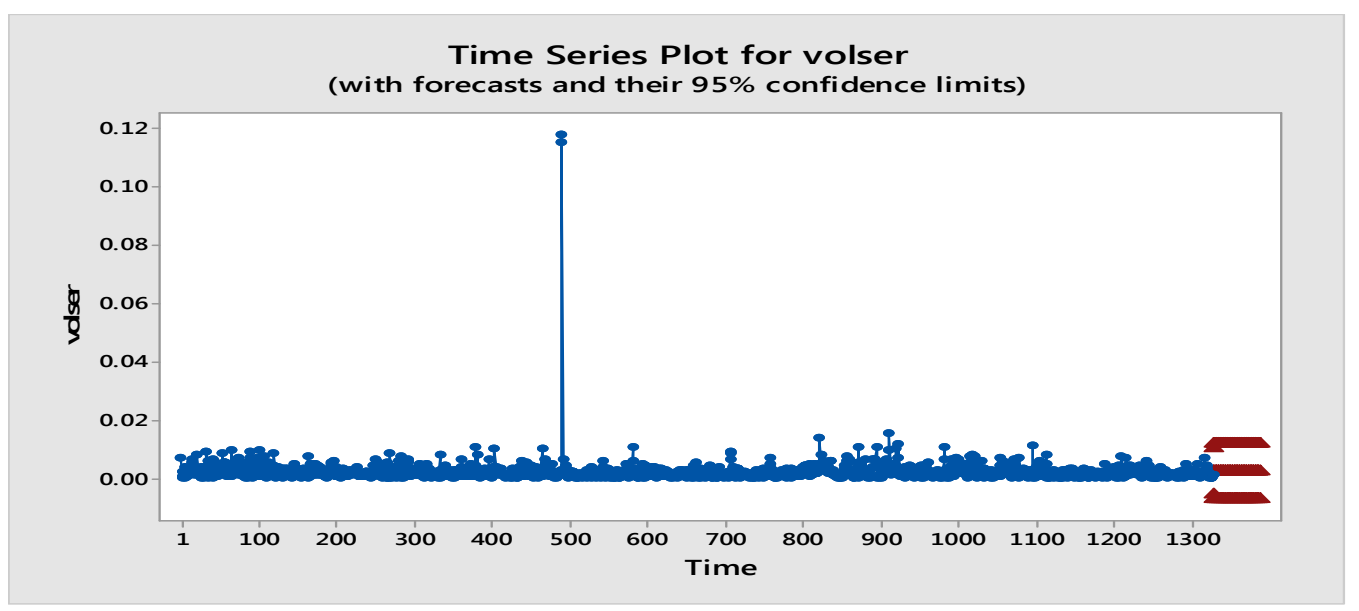

\section{CONCLUSION}

When we can get the petite the forecasting errors, the finest statistical model is said to be generated. There are many factors taken in consideration in the picking of appropriate model. These comprise the accessibility of data and the cost of gathering the data, computer software existed to run the tentative models, the time outline concerned, the nature of forecast preferred(on value or a range of values), and, most important, the diverse mathematical postulations that must be convened with each model. Picking a forecast way to be employed in a particular situation includes finding a technique that, along with practical exactness, poises the factors just scheduled. We concentrate in this sector in ASE because, it is very clear that trade balance of services shows a surplus, indicating that Jordan is successful in services, that implies creating many jobs, most of them more qualified and earning high salaries. Services do not need huge amounts of capital, for example the cost of generating a job opportunity in services does not exceed one third of the cost of generating a job in industry sector. In other words, investment in services is more feasible, with higher return relative to the capital involved.

ARIMA model present a preferred method for many researchers in predicting any oscillated variables. Its control stretch out in the fact that the technique is very suitable for any time series with any outline of change and it does not require the forecaster to select any one of parameters as a move forward. Nevertheless the model has some limitations. One of the limitations is the model necessitate a long time series. Like any other models, this method also does not insure a most advantageous forecasting process. From the other side, it can be effectively employed in predicting long time series data. It has shown that the $\operatorname{ARIMA}(0,0,1)$ found to be the best appropriate model for predicting the volatility of services sector data with the equation $Z_{t}=0.002317+0.622466 a_{t-1}$. 


\section{REFERENCES}

Al-Shiab M. 2006, "The Predictability of ASE Using the Univariate ARIMA Model", Economics Administration Science, vol. 22, no. 2, pp.124- 139.

Andersen, T. , Bollerslev, T., Diebold, F. \& Labys, P. 2003, "Modeling and forecasting realized volatility", Econometrica vol. 71, no 2, pp. 579-625.

Bruce, L. , Richard T. O'Connell and Anne B. 2005, “Koehler,Forecasting time series and regression”, Thomson Brooks/Cole, USA.

Danielsson, J., H. S. Shin, and J.-P. Zigrand .2012. "Procyclical leverage and endogenous risk”.Mimeo, LSE,

.http://www.riskresearch.org

Danielsson, J.et al, 2016. " Learning from History: Volatility and Financial Crises ". http://www.riskresearch.org.

David ,A. and John, C.2003. "SAS for forecasting Time Series, Second Edition". Cary, NC: Institute Inc.

Elena K. \& Storis K. 2009,“Modeling Stock Market Volatility”,Greg N. Gregoriou,stock market volatility,AChapman\&Hallbook,New York.

Enders, Walter 2004, Applied Econometric Time Series (Second ed.). New York:John Wiley. pp. 170-175.

Engle and Granger, 1987,"Co-integration and Error Correction: Representation, Estimation,and Testing", Econometrica,vol55,no.2,pp.251276

Hamao et al, 1990,"Correlations in Price Changes and Volatility Across International Stock Markets", The Review of Financial Studies, vol. 3, no. 2,pp. 281-307.

Geert B and Campbell H,1997,"Emerging equity market volatility", Financial Economics, vol43, pp. 29-77.

Hussein, A, Z,2009, "Asymmetric Volatility Phenomenon: An Application to Major European Countries",International Management Review, vol. 5, no. 1, pp. 37-49.

Hussein.A. Z,2011, "Modeling \& Forecasting Volatility using ARIMA model”, European Journal of Economics, Finance and Administrative Science,vol. 35, pp. 109-125.

John C. and David A.,2003" SAS for Forecasting Time Series, Second Edition. Cary, NC: Institute Inc, pp. 30-193.

Juncal C, Javier, Gomez B,Fernando Perez de Gracia, 2006"Changes in the Dynamic Behavior of Emerging Market:Revisiting the effects of financial liberalization"',Emerging Market Review,Voll7,pp. 261-278.

Mustafa M. Ali A, Shalini B. 2015,"Modeling and forecasting by using time series ARIMA models". International Journal of Engineering Research \& Technology (IJERT), vol. 4 , no. 3.pp. 914-918.

Pankratz A, 1983," Forecasting with Univariate Box-Jenkins Models", Jhon Wiley \&Sons,New York.

Patricia E. Gayner and Rickey C.kirkpatrick,1994,"Introduction To Time- Series Modeling And Forecasting In Business And Economics" Mc Graw-Hill .U.S.

Poon, S.-H., Granger, C.W.J,2003, "Forecasting financial market volatility: A review". Economic Literature,vol. 41, no. 2,pp. 478-539.

Ritab S. Al-Khouri and Moh'd M. Ajlouni, 2007,"Narrow Price Limit and Stock Price Volatility: Empirical Evidence from Amman Stock Exchange" Research, Finance and Economics, vol8, pp. 163-180.

Stephen.S and John.K,2007, “Forecasting volatility in the financial markets”, $3^{\text {rd }}$ edition, Elsevier, pp47.

Websites :

The box-jenkins method-NCSS Statistical Software NCSS.com,LLC

https://en.wikipedia.org/wiki/Unit root test

https://www.otexts.org/fpp/8/1 